\title{
The case study as a means of motivation in the acquisition of technical vocabulary
}

David Thomas

\section{OpenEdition}

Journals

Electronic version

URL: http://journals.openedition.org/asp/4302

DOI: $10.4000 /$ asp.4302

ISSN: 2108-6354

\section{Publisher}

Groupe d'étude et de recherche en anglais de spécialité

\section{Printed version}

Date of publication: 1 October 1993

Number of pages: $273-283$

ISSN: 1246-8185

\section{Electronic reference}

David Thomas, «The case study as a means of motivation in the acquisition of technical vocabulary », ASp [Online], 2 | 1993, Online since 03 March 2014, connection on 03 May 2019. URL : http:// journals.openedition.org/asp/4302 ; DOI : 10.4000/asp.4302

This text was automatically generated on 3 May 2019.

Tous droits réservés 


\title{
The case study as a means of motivation in the acquisition of technical vocabulary
}

\author{
David Thomas
}

1 The theme of this Congress is "Constraint or Liberty", and it is within these terms of reference that I should like to examine the place of the case study in our pedagogical toolbox, having in mind, of course, the teaching of English - or any other language - as a speciality. However, before going any further, it should be pointed out that whilst we have a tendency to call them case-studies, they are in reality yet another example of language teachers picking up someone else's idea and bending it to their own purposes.

2 As far as I have been able to discover, the first case-studies started in Harvard Business School, in about 1910, and have become the principal - if not the only - method of teaching used in the Masters courses. The method involves one teacher and anywhere from 80 to 130 students in a ninety-minute lesson - hardly the sort of conditions that we would look for! An experiment was carried out at HEC in 1988, based on the American system, but using only sixty-five students, apparently successfully.

Before going any further, it would be a good idea to try to define a case study, as applied to language teaching. Whilst there are quite a few definitions, I will offer my own for consideration. It is: "A case study is a submission to a group of students of a situation, real or fictitious, containing an implicit or inherent problem, for analysis, diagnosis, solution or any combination of the three, in a foreign language".

4 Next, my hypothesis which is that the use of case studies liberates students from the dreary task of learning long lists of specialised vocabulary. I shall try to prove this to you. To do so, it is first necessary to situate my public, which is mixed. I concentrate on 2nd year students in the Commercial Techniques Department (TC) of Caen IUT, but I also use the tool when teaching Company Management and Administration (GEA) students in the 
same establishment, 1st and 2nd year ESC students and, finally, 3rd year Applied Foreign Languages students in Caen University, a total of some 450 students annually.

Identification of the problem is important. It is, basically, the difficulty faced by the average student in acquiring specialised vocabulary. This is true of any sector which uses its own specialised language, although it might be reasonable to ask ourselves once again just what a specialised language is. Let us take the case of Business English, as touted around by all the educational publishing houses. Basically it is nothing more than everyday English and a certain number of technical terms. I appreciate that this remark may raise a few hackles, not unreasonably, let's just accept it as a generality for the moment.

Why is this vocabulary acquisition difficult? To answer that, we have to examine how words are learnt. The basic answer is by creating an association of ideas between the word and an image in our minds. Take, for instance, the word "shoe". This is not a problem, our minds immediately present us with the mental image of the objects we wear on our feet (I am using only nouns as examples, in order to avoid complication.) In other words, we have a product - the mental image - and a label - the word - to hang on it. The association of the two makes long-term retention easier. The problem occurs when the student has no product to hang the label on. You might like to try this experiment: walk into any 1st year class of an IUT and ask the students, "Qu'est-ce qu'un connaissement?" Notice I used their native language. If you are lucky, over a sample of 100 students you will find about $5 \%$ who think they know. Now give them the translation, "a bill of lading." It is very difficult for the majority of them to remember it beyond the end of the lesson, simply because it doesn't mean anything to them, they have no object to hang the label on.

7 of course, once you have given them the meaning of a bill of lading, their task should be easier. In fact, it is not, or not much. They see shoes every day, but they have never seen a bill of lading, much less used one. What is more, they do not particularly care, because they are not sure that they will ever need to know. In other words, we are up against a lack of motivation. Create the motivation, the need to know, and the retention rate will go up by leaps and bounds. Add to this the use of the term in its professional context, or, if you prefer, the instructions for use, and the memorisation will improve even further.

Since time is limited, I will not go into detail on the need for appropriate classroom work in preparation for the use of a case study, I think it is self-evident. Suffice it to say that unless the ground-work is done, the case study will lose a lot of its effectiveness.

We come now to the somewhat vexed question of the case study itself, because although we have offered a rather clinical definition, we need to look at it more closely, and also endeavour to track this elusive beast to its lair. First, it has to be said that there are case studies available commercially - one example is Harrap's Agenda (Cotton \& Owen 1980) and they undoubtedly have their merits. They do, nevertheless, have their drawbacks. One is that they may not be suitable because the subject matter does not correspond to our needs. The second is the level of difficulty of the contents, which again may not be suitable for a given public.

The solution, of course, is to write our own, adapted to the needs and the level of our own students. The reaction to this may be: "But we can't do that, we're not competent, we don't have the necessary specialised knowledge, etc., etc." Far be it from me to belittle 
the inherent dangers and pitfalls of such an undertaking, but the task is quite feasible, if we go about it in the right way.

11 Being of a resolutely practical turn of mind, as opposed to an abstract thinker, I would like here to use a concrete illustration, based on a very recent experiment. Any case study needs a starting point, which can be a product, a service or a situation - again I am simplifying things. Having recently given a series of lessons on the mechanisms of publicity - use of an advertising agency, budgeting, planning a campaign, etc., - I decided to finish off with a mini case study. Now, it seems obvious to me that it is no use expecting students to work out an advertising campaign for Peruvian Pan pipes tuned to the key of B flat. In the first place, the market niche for Pan pipes is not all that big, and secondly I have the feeling that my students might have some difficulty in identifying with the product - it is not exactly an everyday item. This leads us straight away to the elaboration of a couple of rules: one, the situation must be as realistic and credible as possible and two, the product must interest the greatest possible number of students

Just what are our students interested in? The answer is blindingly simple: ask them! They're the ones who know. I simply took a straw-poll of what product they were interested in, and then obtained - forced might be a better word - a consensus. The TC students went for Scotch whisky, the GEA for Swatch.

The next rule applies more to the teacher than the students although, as you will see, their aid is necessary. It is a simple rule: document yourself. Having chosen the subject, read everything you can lay your hands on on the matter. It is true that you may not have the time to do the research, there are only 24 hours in the day. So don't do the research yourself - get the students to do it for you! It is their subject, they chose it - more-or-less - so start them working on it straight away, maintain that level of motivation you have already created. Ask the students (each group of students, in reality, because they should ideally work in groups of four or five) to constitute a file of press and magazine articles on the chosen subject, to be submitted to you by a given date. Normally the majority of the documents should be in English - Time, Newsweek, the Economist, Vocable, etc. - but do not exclude other languages, especially French. Remember, part of the object of the exercise is for you to obtain as much information as possible. I say part of the object, because this documentary research has a second advantage, it forces the students to read in a foreign language, which can only be beneficial. Once all the files have been handed in, settle down and read everything - not an unpleasant task. You will be surprised how rapidly you become an expert on the matter!

14 I must apologise for what comes next: I cannot offer you a hard-and-fast methodology on finding the actual subject. I honestly do not think there is one. The best thing you can do is absorb as much information on the given subject as possible, and then simply let that fantastically intricate mechanism, your brain, churn it all around and throw up an idea. And it will, in time. It may come in a flash, it may come to you slowly, over a period of days or even weeks. Don't worry, it will come eventually.

Now we come to another rule: don't hesitate to manipulate the facts. Remember my two products, Swatch and whisky. In the case of Swatch, I was not quite sure what we could do. Finally I decided to massage the truth a little and pretend that Swatch was losing market shares to Benetton and needed to do something to redress the situation. I asked the students what they thought the company should do. Their solution was to 
launch a new product. What product? Again, get them to do the work, it is often quite amazing how rapidly their fertile and collective imagination comes up with things. In this case it was a Swatch which changes colour with the ambient temperature and which does not make that horrible TICK-TACK noise! I threw in a new, environmentally friendly and non-polluting battery that I invented especially for the occasion, and the subject quite literally found itself: plan an advertising campaign to launch this new product. In the case of whisky, things were easier, since, whilst visiting trainee students in companies in Scotland last spring, I went round a couple of distilleries so I had a little knowledge of the matter. A very up-market range of twenty-year old single malt became the object of the other advertising campaign.

(Incidentally, three days after launching the Swatch case study, I came across an article in a newspaper saying that Swatch had just had a record sales year. You can't win them all! The important thing to note is that it didn't worry the students, since the scenario I had invented was realistic and credible.)

The next task is to select appropriate documents from the collection to illustrate the case study. Again, methodology is difficult, if not impossible, to formulate. It is really extremely difficult to codify such a subjective matter. Here I would like to enter a plea for common sense and feeling. As academics we are constantly trying to reduce everything to formulae and equations, and I am not convinced that this is necessarily always a good thing. Up to a certain point, yes, it is undoubtedly helpful, but beyond that point my own opinion is that instinct should play its role. You simply cannot codify something that feels right to you. An illustration would be my pastime, which is designing and flying R/C aeroplanes. Since I do have a fairly solid grounding in aeronautical science, I go by the book most of the time, but there are occasions when I just cannot find the necessary scientific information, and I work on the well-known principle of: if it looks right and it feels right, it probably is right. There is a lot to be said for it. I will concede that the criterion is arguable, but classroom experience in this field would appear to bear out the validity of the statement.

What normally happens is that you read all the documents on the subject and find that a number of them appeal to you, perhaps because of the style, or the contents, or both. Put them to one side. When you have finished, read the attractive ones again and the same process will repeat itself. Now evaluate the remaining articles for general interest, specific interest, clarity of contents, style and any other criteria you feel relevant. The original pile of documents will eventually be whittled down to a very small number.

We should now have two or three articles - authentic documents, and we all know how important they are in lending credibility to a classroom situation - to illustrate the case. (No more than four, otherwise the students will have to spend too much time reading and interpreting them.) I recently received documentation from the Centrale des Cas et des Médias Pédagogiques in Paris, and was interested to see how closely the empirical method just described aligns itself with their prescribed system of writing case-studies. Were I not worried of being accused of boasting, I might go as far as to quote the saying; "Great minds think alike", but it would probably be far wiser to quote another one: "There's nothing new under the sun"!

20 You will have to decide what kind of case study you want to create. Once again, in order to simplify things, we can define three basic types:

A. Diagnostic (In other words, define the problem.)

Example: Swatch are losing market shares. Why? 
B. Solution (In other words, solve the problem.)

Example: Swatch is losing market shares. What should be done?

C. Analysis (In other words, analyse the situation.)

Example: Swatch is losing market shares, it launches a new product, and continues

to lose ground. Why?

From this starting point we can now look at the advantages and drawbacks of each type.

A. The situation can be simple, but with complex ramifications.

This gives everyone something to say. On the other hand, there is rarely a final solution, so unless the teacher is very careful the debate may go around in circles.

B. There is plenty to talk about, the solution provides a finality, it is easier to evaluate. The drawbacks are twofold; in the first place there is a need for a considerable amount of detail, and secondly some students shy away from finding a solution, in case they are wrong.

C. Very complete, the students can discuss not only the problem, but also whether it was correctly analysed and if the given solution was appropriate. However, it is necessarily very complex, requiring not only a high degree of linguistic skill, but also a solid knowledge of the specialised field, both by the students and the teacher.

Naturally, any combination of the above-mentioned types is possible, your choice will depend essentially on two factors: how confident (and competent) you, the teacher, feel and the capacities of your students.

Once again, there are no hard-and-fast rules governing this choice - it is a question of personal judgement, of deciding what is best suited to your own and your students' abilities and needs.

Having decided what kind of case study you want, your inventive talents now come into play. It is rather like writing a scenario for a short play, and again it is up to you how you go about it. There is one general rule that must be respected: make it as realistic as possible. The students must believe in it. The moment they stop believing, they will lose their motivation, and you have lost the game. It is a good idea, when you have finished writing it, to put it away in a drawer somewhere and forget all about it. After a week or so, take it out and re-read it with a fresh, analytical - I would even say critical - mind. Is it interesting or is it boring? Does it ring true to you? If it is boring, or seems unlikely, then you need to do some more work on it.

28 A word of warning: avoid figures like the plague! Because figures are an exact science, students tend to clutch hold of them like a drowning man holding onto a lifebelt, and they will turn your English lesson into a maths lesson before you know where you are. An easy way to do this is to give them a global figure - the budget for an advertising campaign, for instance - and ask them to divide it up in terms of percentages. (You will probably find that Finance students insist on presenting long tables of figures anyway. Do not stop them from doing so, it is after all their speciality, but warn them that they will be expected to explain the figures...in English!).

Do not hesitate to introduce characters into the story; Mr Highflight from the Advertising Agency, with his way-out ideas and loud suits, Mr Postlethwaite, the elderly, reactionary Managing Director full of old-fashioned ideas about fairness in business, and so-on. Do not hesitate to make them larger than life, even outrageous, the students will love them. There is a current tendency for authors of case-studies to portray everything in terms of black and white, but life just is not like that, there are all the shades of grey in 
between. If Mr Brown has got big ears or Miss Jones has got a funny, squeaky voice, say so, it adds reality.

Having got your main plot, the next thing to do is to lay down the instructions, but before doing so, you have to decide exactly what you want from your case study. The traditional thinking is an oral expose, and this is fine, though I must admit that I almost invariably add at least one written document to be produced by each group. In this way both oral and written competences are tested.

Decide whether you want each group to do exactly the same thing, or whether you want some diversity. I have to confess that last year, without of course knowing what the theme of this Congress was going to be, I wrote a case study which obliged every group to do exactly the same things. This was fine, it made comparative marking easy, but we had to sit through 42 groups doing the same exposé, which does not make for easy concentration. This year, having learnt of the theme, I decided that the watchword would be liberty and wrote a new case study, in such a way that there are an unlimited number of choices for the oral exposé, whilst remaining within the terms of reference of the basic situation. The orals will take place over the next three weeks, so I am unable to provide any feedback at this time. However, during the preparation phase I have had the distinct feeling - there's that word again! - that the students are more than somewhat perplexed because of this range of choice. Indeed, some groups have had difficulty in making up their minds about what specific subject to tackle. Whatever else, this year's case study will be a good exercise for them in decision-making! For the moment I am far from being convinced that total liberty - at least in this area - is necessarily a good thing.

This having been said, a case study does not have to end inevitably with an oral exposé: in the case of Swatch and Scotch whisky I asked my students to write a report to the Management, detailing their draft project.

When you have made up your mind, write the instructions, in English, of course. Here we find another rule - you can never be too precise when writing instructions. You may read them over and over, adding something each time round. When the students get hold of them, if there is an omission or a loophole, you may be sure that they will find it! Be prepared to answer questions, sometimes awkward ones. This has in fact happened to me this year: my instructions to write a two-page report on the ideal commercial policy of the company in question over the next year was formulated in such a way that it was ambiguous. It may well be that taking a leaf from the marketing people's book and pretesting the instructions - on a colleague for instance - could eliminate this sort of error to a great extent.

In these instructions you should indicate what form you want the oral to take. Personally I favour role-play, simply because it again gives more scope for realism, and it also allows the students to be as professional as possible. Limit them to a maximum of two roles per person, use lapel or table badges to indicate clearly who they are, encourage them to use props and to dress the part. One of the best orals it has ever been my fortune to see was given last year, when four male students played out a business lunch. They set a table with cloth, cutlery, porcelain, candles, wine, etc. They were all four dressed in smart suits and ties - which was a triumph in itself! - and their parts were beautifully rehearsed.

Some of you may immediately leap upon the word "rehearsed" and wonder whether that is the right thing to do. My feeling is that if they have spent hours rehearsing, they are 
not going to forget the vocabulary they used in a hurry, and that is, after all, the object of the exercise.

The preparation phase is crucial. Set the students, in their small groups, at separate tables and let them get on with it. I do not think it is a good thing to force them to talk English during this time, it slows the operation down too much. Your job is to wander round and listen. Don't be obvious about it. Look out of the window, pretend to be checking something in a book, at least at first. Initially, the moment you go near a group they will fall silent - the usual syndrome, "If I say something stupid when the teacher is within earshot, he's likely to jump down my throat, so, to be safe, I'll say nothing." A perfectly normal reaction. This leads us to yet another rule: never, ever criticise. If you do, they will lose confidence in both themselves and you. If you do hear something erroneous or stupid, pick it up and suggest that maybe it is not the best idea, perhaps it would be better to tackle the thing this or that way. Lead them on, encourage them, if necessary, push them, but never criticise. And before the word demagogy leaps to anyone's lips, forget it, it is not the case. This is a matter of instilling confidence. The students have to realise that you are there in the capacity of a guide and mentor and not that of Mr Wackit. It may take a while, but if you persist they will get the message and talk openly when you are within earshot. Eventually they will start asking you for your opinion or advice; this is, of course, the ideal situation.

Get them to keep a journal, or log-book. In it they should write down everything they do during each work-session. This serves a double purpose: it allows you, the teacher, to know just where they are in their preparation, and secondly it makes them more aware of the amount of work left to do before the date of the expose. The latter is very important, I have seen groups in a state of absolute panic because the date had crept up on them unseen, as it were, and they were not ready. This is to be avoided at all costs. It is also a good idea to ask them to note all their work sessions outside normal classroom hours, you will be surprised to see just how much time the more motivated groups spend on preparation and rehearsal.

Choose a suitable room for the oral, not the usual classroom with the chairs and tables piled up along the walls, they cannot be expected to act professionally in such a setting. Try and find a conference or similar room. This year I have obtained the use of the IUT's big Board Meeting Room - against all the odds! - and this is ideal.

On the day of the oral, greet each group as they arrive calmly and in a friendly manner, but avoid being too familiar with them, in a mistaken attempt to put them at their ease. This can lead to a feeling of over-confidence on their part. Ideally they should be on their mettle, but not stressed. Do not forget how scared you were the first time you had to get up and speak in public - they will be feeling exactly the same. Be relaxed, cool, as they say, try to put them at their ease, but keep your distance.

Different people will see this in different ways, but my personal opinion is that it is better to let each group carry out their oral in front of the jury alone, and not with the other members of the class present. This is an arguable point, and one that you will have to decide for yourself. So is the rather vexed question of marking. To mark or not to mark? Without wishing to resuscitate the age-old polemic, it would seem that we can consider marks to be either a stick or a carrot. My personal opinion is that they are both; for the lazier students they constitute a threat, for the more willing ones they are a reward. After all, students need good marks in their academic cursus and it would be unfair to deprive 
them of the chance of earning some. That may well sound like a tongue-in-cheek remark, but in fact I believe it to be an accurate one.

Given the not-inconsiderable difficulty of marking both content and form, I always try to co-opt another English teacher to help me - it gives more weight and solemnity to the whole thing, we each specialise, one on content, the other on English, but both have a right to a global, and, let's face it, subjective judgement.

To sum up, I would say that for myself the orals are amongst the most rewarding moments in the teaching year. I am constantly amazed at the performances of students who I had hitherto considered as not being particularly brilliant. The sense of occasion, the solemnity, the fact that the other members of the group are depending on them, the reality of the situation, all bring out the best in them. In a word, they are motivated. of course, there are accidents, there always will be, they are inevitable, but they are quite rare.

Naturally, all this means a lot of hard work and preparation for the teacher, but in recent years I have talked it over with the students afterwards and have the very strong feeling that it is worthwhile, that they learn something from the experience, and, to be honest so do I. The case study is only one tool among many in our toolbox, but I, for one, am convinced that it is an efficient one, that it liberates the student from the task I always hated in my youth, that of learning vocabulary by rote.

\section{BIBLIOGRAPHY}

Cotton, David and Roger Owen. 1980. Agenda, Casebook. London: Harrap \& Co.

\section{ABSTRACTS}

The use of the "in the acquisition of specialised vocabulary is a source of student motivation. Technical terms, when used in simulated situations which reflect the real-life context, render the task of retention much easier than the traditional method of learning by rote. Authentic documents on the core subject bring realism to fictitious situations and encourage a professional presentation of the resulting exposé. The writing of case studies is well within the scope of ESP teachers, who can make full use of students' abilities in order to help them in their search for suitable subjects and scenarios.

L'emploi de l'étude de cas dans l'acquisition du vocabulaire technique est une source de motivation pour l'apprenant. Les termes techniques, employés dans une situation fictive qui reflète le contexte réel, rendent la tâche de l'assimilation du vocabulaire plus facile que par la méthode traditionnelle qui consiste à apprendre des listes de mots. Des documents authentiques sur le sujet de base ajoutent du réalisme aux situations fictives et encouragent une présentation professionnelle de l'exposé qui en résulte. L'élaboration des études de cas par des enseignants d'anglais langue de spécialité est tout à fait à leur portée, et ils peuvent utiliser pleinement les talents des apprenants dans leur recherche de sujets et de scénarii appropriés. 
INDEX

Mots-clés: document authentique, étude de cas, motivation, vocabulaire

Keywords: authentic document, case study, vocabulary

\section{AUTHOR}

DAVID THOMAS

IUT de Caen, Départements TC et GEA. 